Journal of Electronics and Informatics (2020)

Vol.02/ No.03

Pages: $155-161$

http://www.irojournals.com/iroei/

DOI: https://doi.org/10.36548/jei.2020.3.001

\title{
PLC Batch Process Control Design and Implementation Fundamentals
}

\author{
Khaled Kamel \\ Computer Science Department, \\ Texas Southern University, \\ Houston, TX \\ Eman Kamel \\ PLC Automation, \\ Manvel, TX
}

\begin{abstract}
Batch process control is typically used for repeated chemical reaction tasks. It starts with a measured liquid material filling operations followed by a controlled reaction leading to the discharge or transport of processed quantities of material. The input materials is contained in vessel reactor and subjected to a sequence of processing activities over a recipe predefined duration of time. Batch systems are designed to measure, process, and discharge a varying volume of liquid from drums, tanks, reactors, or other large storage vessel using a programmable logic controller (PLC). These systems are common in pharmaceutical, chemical packaging, Beverage processing, personal care product, biotech manufacturing, dairy processing, soap manufacturing, and food processing industries.
\end{abstract}

This paper briefly discusses the fundamental techniques used in specifying, designing, and implementing a PLC batch process control $[1,2]$. A simplified batch process is used to illustrate key issues in designing and implementing such systems. In addition to the structured PLC ladder design; more focus is given to safety requirements, redundancy, interlocking, input data validation, and safe operation. The Allen Bradley (AB) SLC 500 PLC along with the LogixPro simulator are used to illustrate the concepts discussed in this paper. Two pumps are used to bring in material during the tank filling and a third pump is used to drain processed product. The three pumps are equipped with flow meters providing pulses proportional to the actual flow rate through the individual pipes. The tank material is heated to a predefined temperature duration followed by mixing for a set time before discharge.

Batch control systems provides automated process controls, typically and universally using PLC's networked to HMI's and other data storage, analysis, and assessment computers. The overall system perform several tasks including recipe development and download, production scheduling, batch management and execution, equipment performance monitoring, inventory, production history and tracking functionalities. Flexible batch control systems are designed to accommodate smaller batches of products with greater requirements / recipes variation, efficiently and quickly. In addition to providing process consistency, continuous batch process control quality improvements are attained through the automatic collection and analysis of real-time reliable and accurate event performance data $[3,4]$.

\section{Batch Process Description}

In this illustration a small and abbreviated part of a real batch automation project involving the heating and mixing of two liquid chemicals in certain amounts and under pre-specified conditions. Figure 1 shows the main page of an HMI representation of the implemented system using Allen Bradley SLC 500 LogixPro simulator [5, 6]. The main goal of this paper is to demonstrate batch process control structured ladder logic with emphasis on key safety and quality design issues.

ISSN: 2582-3825 (online) 
Journal of Electronics and Informatics (2020)

Vol.02/ No.03

Pages: $155-161$

http://www.irojournals.com/iroei/

DOI: https://doi.org/10.36548/jei.2020.3.001

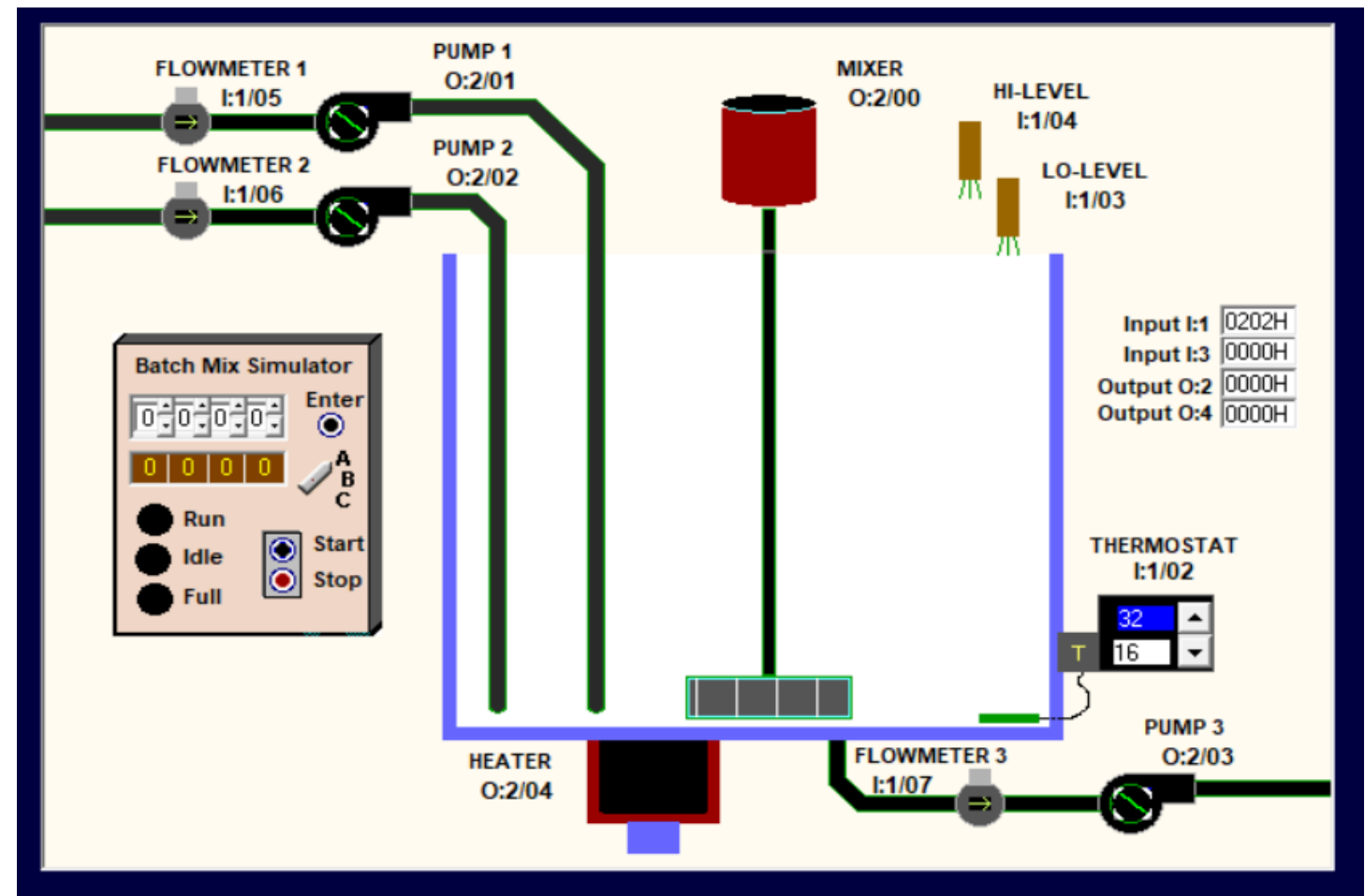

Figure 1 Batch System Main HMI Page

The following tables list all inputs, outputs, and internal reference addresses used in this abbreviated batch control task; physical address, tag name, and the associated functions.

\begin{tabular}{|l|l|l|l|}
\hline Name & Address & Tag Name & Type \\
\hline Flow meter 1 & I:1/5 & Flowmeter 1 & Pulses \\
\hline Flow meter 2 & I:1/6 & Flowmeter 2 & Pulses \\
\hline Flow meter 3 & I:1/7 & Flowmeter 3 & Pulses \\
\hline HI-LEVEL & I:1/4 & Level Float Sensor & Level \\
\hline LO-LEVEL & I:1/3 & Level Float Sensor & Level \\
\hline Thermostat & I:1/2 & Thermostat & Temp. Element \\
\hline Mode Selector & I: $1 / 9$ & A (AUTO) & Selector Switch \\
\hline START PB & I:1/0 & START & NO Push Button \\
\hline STOP PB & I:1/1 & STOP & NC Push Button \\
\hline Level Set Point & I:3 & Batch Mix Simul. & 4 Digits BCD \\
\hline \multicolumn{2}{|l|}{ System Outputs } & \\
\hline Name & Address & Tag Name & Function \\
\hline Pump 1 & O:2/1 & Pump 1 & Inlet/Fill Pump 1 \\
\hline Pump 2 & O:2/2 & Pump 2 & Inlet/Fill Pump 2 \\
\hline Pump 3 & O:2/3 & Pump 3 & Discharge Pump 3 \\
\hline Mixer & O:2/0 & Mixer & ON/OFF Mixer \\
\hline Heater & O:2/4 & Heater & ON/OFF Heater \\
\hline Level Measurement & O:4 & Batch Mix Simul. & 4 Digits BCD \\
\hline
\end{tabular}

ISSN: 2582-3825 (online) 
Journal of Electronics and Informatics (2020)

Vol.02/ No.03

Pages: 155-161

http://www.irojournals.com/iroei/

DOI: https://doi.org/10.36548/jei.2020.3.001

\begin{tabular}{|l|l|l|l|}
\hline RUN Light & O:2/5 & RUN & ON/OFF LIGHT \\
\hline IDLE Light & O:2/6 & IDLE & ON/OFF LIGHT \\
\hline FULL Light & O:2/7 & FULL & ON/OFF LIGHT \\
\hline \multicolumn{3}{|c|}{ Internal References } \\
\hline Address & Function \\
\hline T4:0 & Mixer Timer \\
\hline C5:1 & Pump1 Flow Pulse Counter \\
\hline C5:2 & Pump2 Flow Pulse counter \\
\hline N7:10 & P1 and P2 Cumulative value \\
\hline B3:2/4 & Heater Start Trigger Bit (SP Equal Level) \\
\hline
\end{tabular}

\section{Ladder Logic Implementation}

Three subroutines were implemented to realize the process control specifications; START_UP (U3), LEVEL_UPDATES (U4), and PROCESS_CONTROL (U5). The U3 subroutine function shown in Figure 2 is to reset all timers / counters / registers used in the program. This action only takes place during the first scan or after the activation of the start PB. The tank level set point (SP) is taken from the 4 BCD thump wheel input switches. The U4 subroutine shown in Figure 3 implements the logic for updating the tank level. Pulses from the inlet pumps flow meters increment the level count while pulses received from the discharge pump decrements the level count. The U5 subroutine in Figure 4 shows the batch process control sequence implementation. The batch operation initiate after activation of the START PB while the AUTO selector switch is maintained ON. It can be stopped by activation of the STOP PB at any time. The tank is filled by the flow from the two inlet pumps to the requested level SP or until the flow is shut by the trigger of the high level sensor. This is followed by heating to the requested temperature SP and finally mixing for a simulated 10 seconds duration. The processed liquid is drained until the low level sensor is triggered. Three different light indicators are managed during the batch operation.

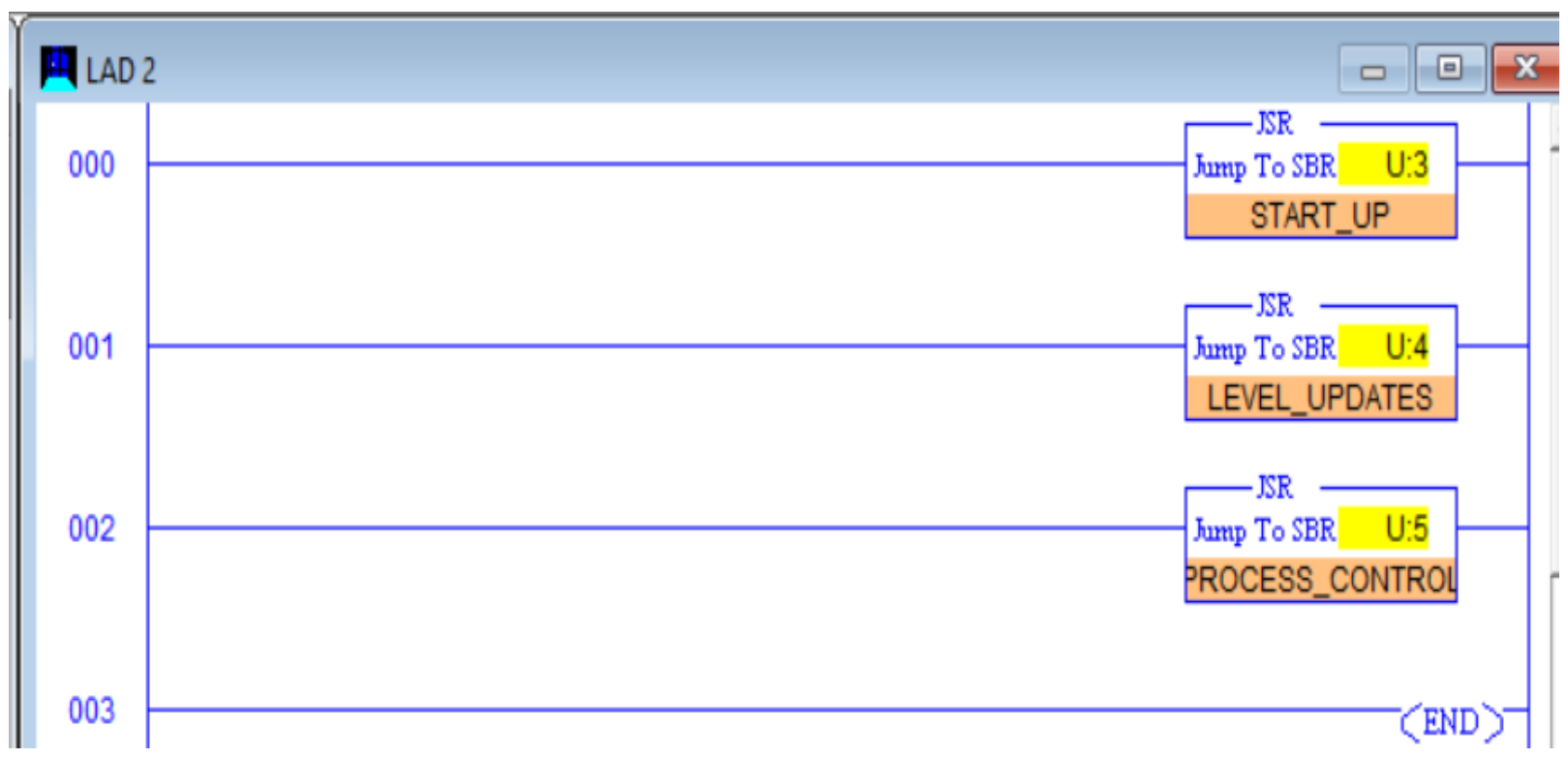

ISSN: 2582-3825 (online) 
Journal of Electronics and Informatics (2020)

Vol.02/ No.03

Pages: 155-161

http://www.irojournals.com/iroei/

DOI: https://doi.org/10.36548/jei.2020.3.001

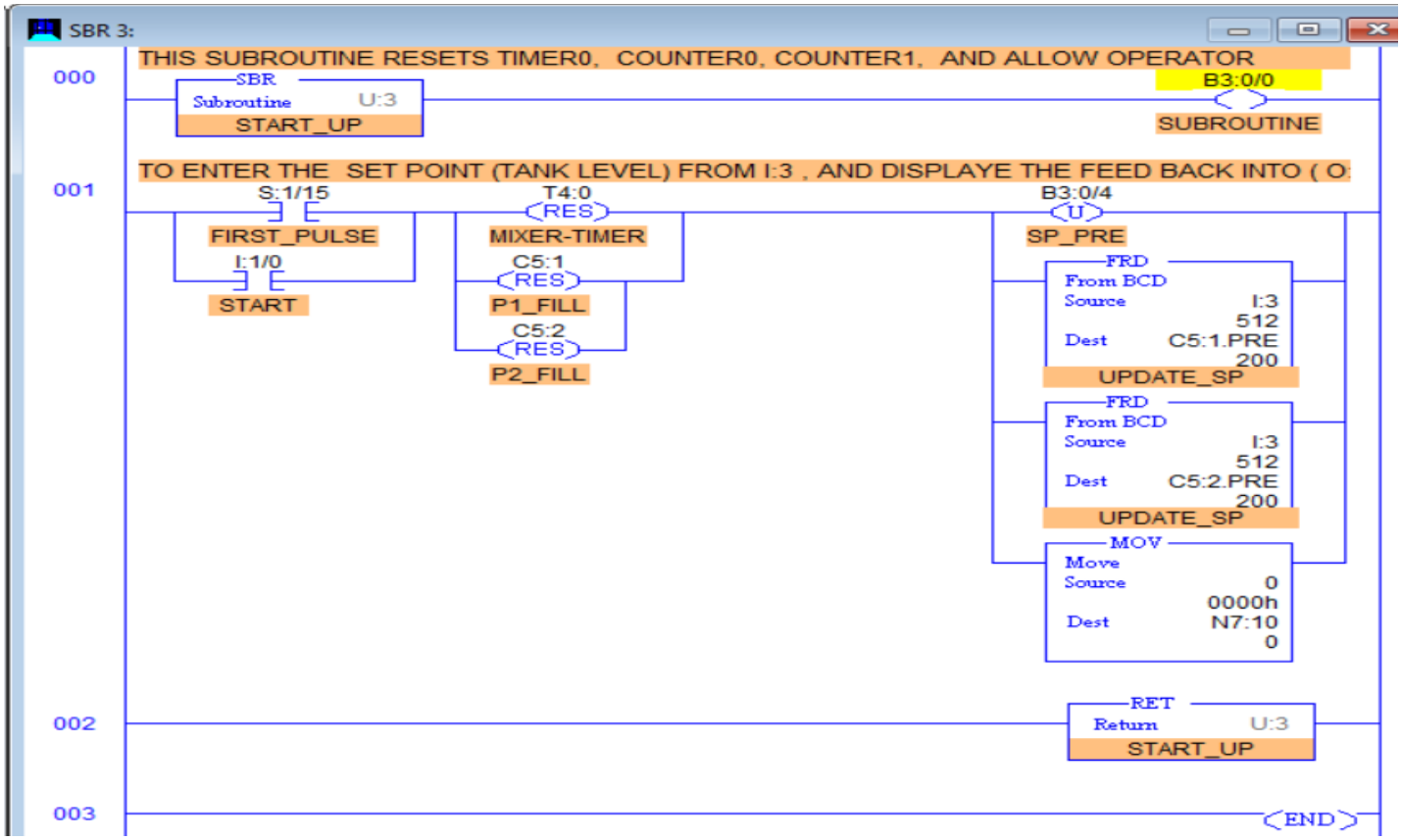

Figure 2 Startup Subroutine U3

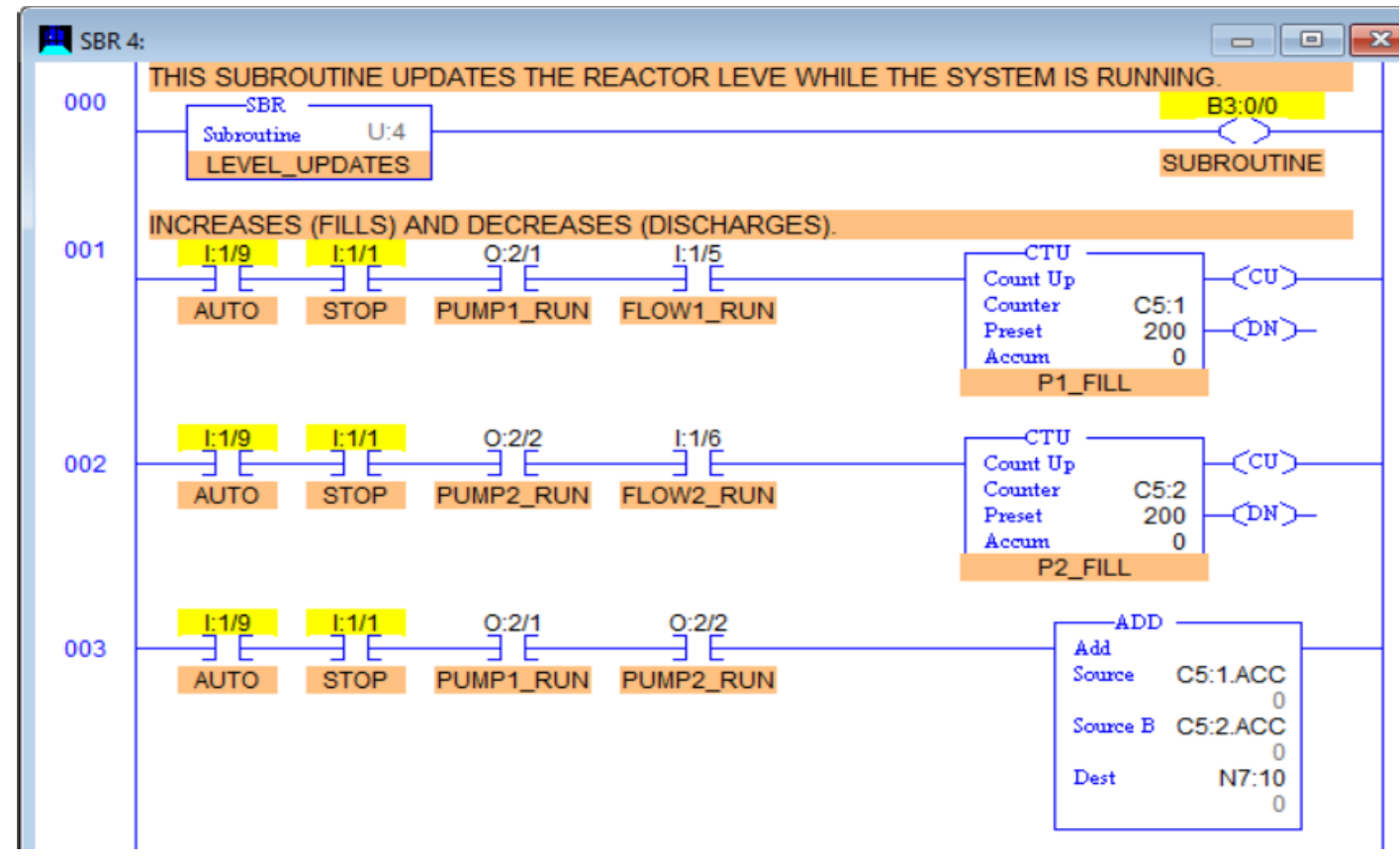

ISSN: 2582-3825 (online) 
Journal of Electronics and Informatics (2020)

Vol.02/ No.03

Pages: 155-161

http://www.irojournals.com/iroei/

DOI: https://doi.org/10.36548/jei.2020.3.001

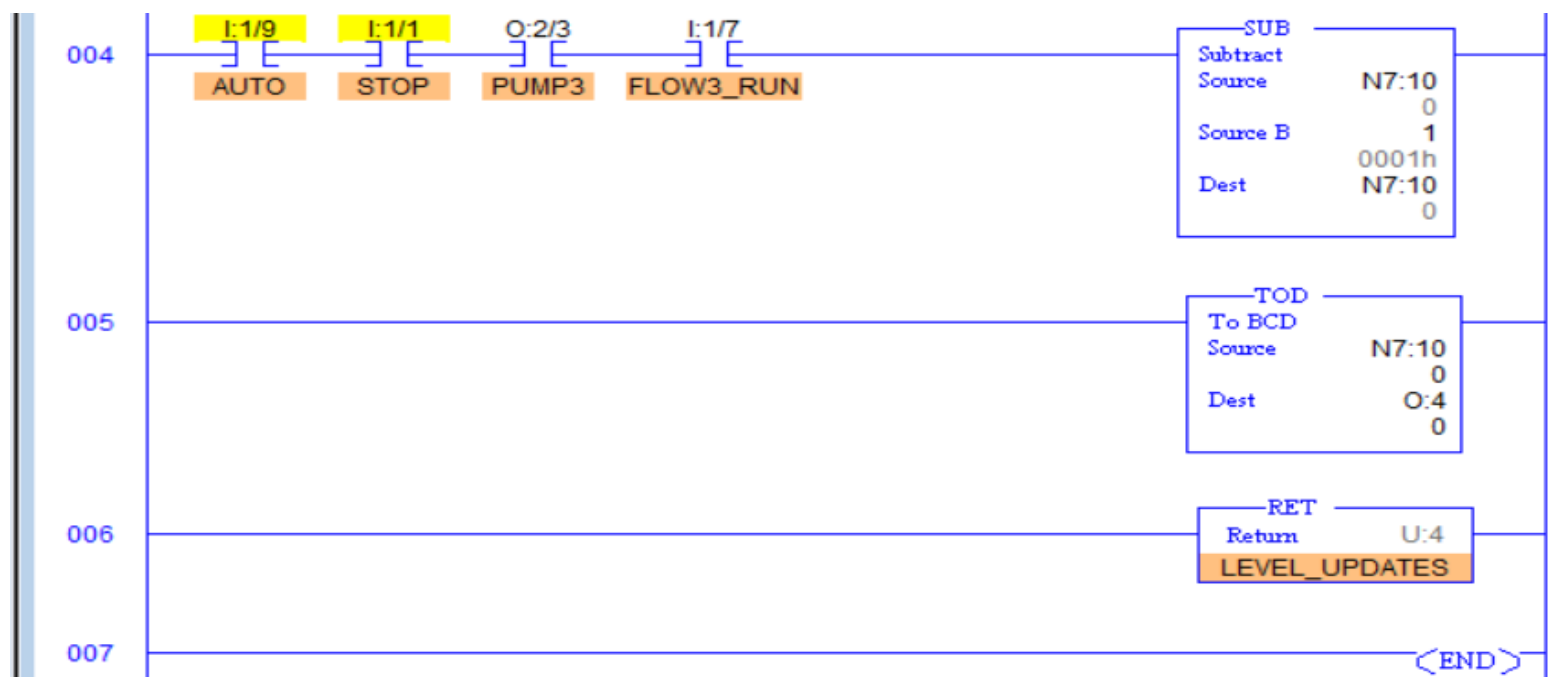

Figure 3 Tank Level Update Sub routine U4

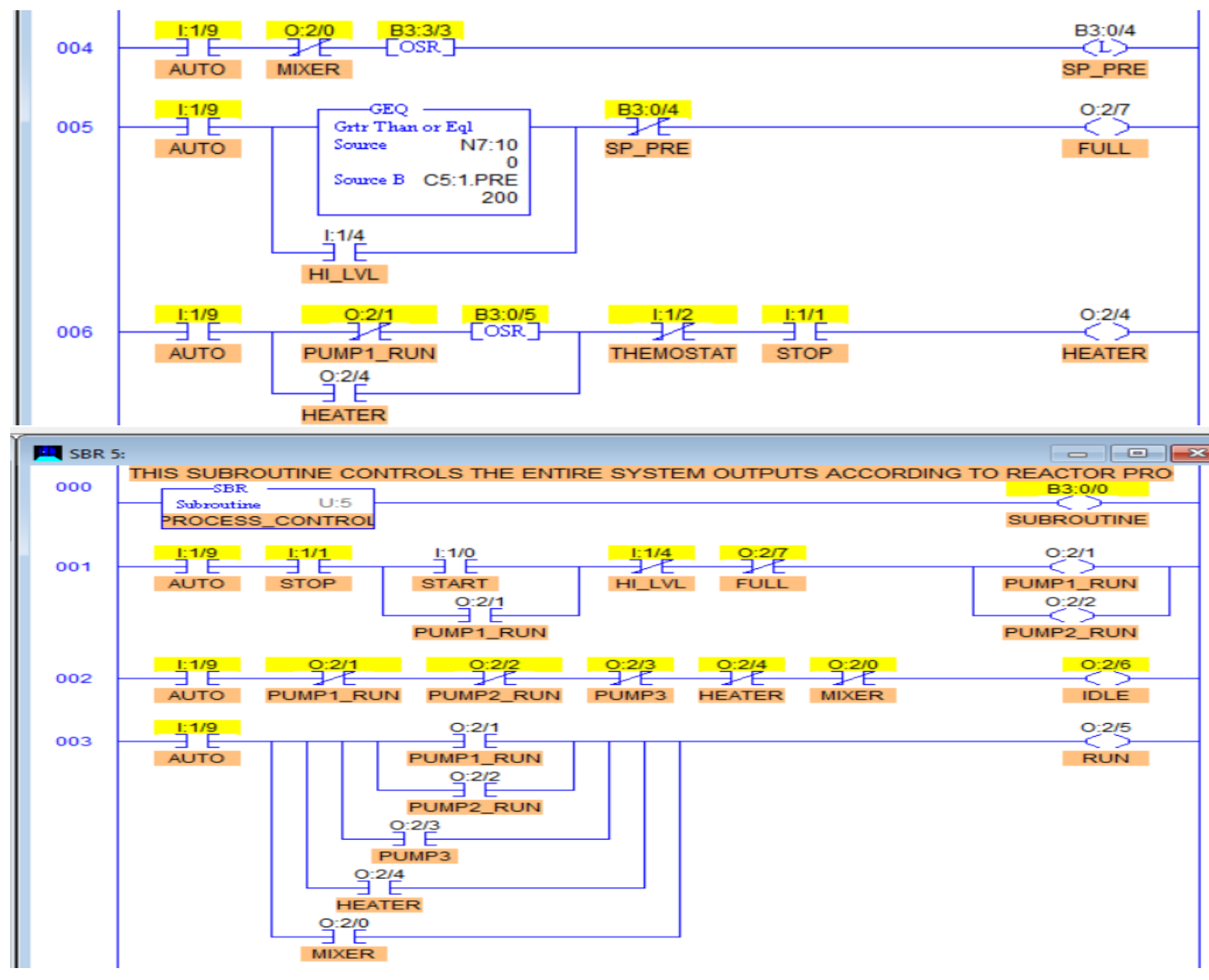

ISSN: 2582-3825 (online)

Submitted: 14.04 .2020

Accepted: 01.06.2020

Published: 09.06.2020 
Journal of Electronics and Informatics (2020)

Vol.02/ No.03

Pages: $155-161$

http://www.irojournals.com/iroei/

DOI: https://doi.org/10.36548/jei.2020.3.001

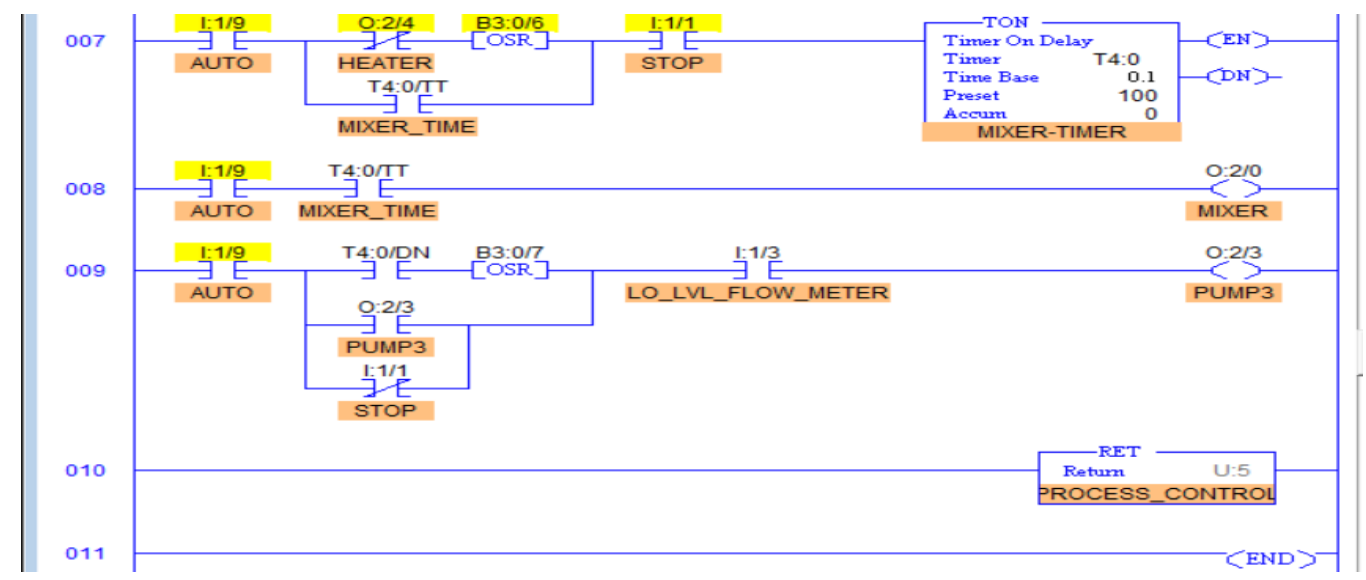

Figure 4 Batch Process Control U5

\section{Design and Safety Considerations}

Safety is a major consideration in designing and implementing batch process control. Most safety related issues are covered through enforced national and universal standards including the ISA 88 standard [7]. The operation of industrial motors and pumps must be done using normally open momentary push button switches and normally closed stop push buttons. These requirements are needed in addition to other mandated motor starter and mounted protections. Batch process requires accurate ingredient measurements, which can be achieved using human error, appropriate sensors with adequate degree of redundancy. Spillover of dangerous chemicals must be prevented, not only by software means but also through the use of redundant hardware. The use of the high level sensor to shut the fill pumps will prevent spillover due to human error, sensor malfunction, or wrong level calculations. The use of the low level sensor will prevent the discharge pump from damage due to possible run on low level or empty tank. Typically more redundant and complementary sensors are used such as high level and very high level or low level and very low level; each prompting different control strategy and action. None of these were implemented in this paper example.

Automated batch system still requires human monitoring and interactions at all times. Absolute safety throughout the operation is a must including immediate reaction to unpredicted events and user actions. The operator can stop the operation including all actuators for an observed up normality or interference. The software must be designed to hold the process in a safe state as defined by the system expertizes. In the shown implementation, the control system discharges the tank liquid after a stop activation. This was done to minimize any potential harm from excessive material reaction or other potential dangers. If the AUTO selector mode is switched off during batch processing, another safety option was implemented to halt the operation while other manual interventions and interactions are taken place. Once the AUTO mode is restored, the process continue from where it was halted. These kind of safety reactions and precautions will vary from one implementation to another but al ways guided by the best practices defined by the collective domain expertise. Those expertise can span electrical, mechanical, chemical, structure, environmental, and many other domain areas.

ISSN: 2582-3825 (online)

Submitted: 14.04 .2020

Accepted: 01.06.2020

Published: 09.06.2020 
Journal of Electronics and Informatics (2020)

Vol.02/ No.03

Pages: 155-161

http://www.irojournals.com/iroei/

DOI: https://doi.org/10.36548/jei.2020.3.001

\section{Conclusion}

This paper briefly discussed the fundamental PLC batch process control techniques including ladder logic simulation, safety precautions, and standards. An abbreviated two inlet pipes and one outlet pipe batch process control was used to demonstrate the PLC implementation structured technique and the associated safety precautions. The batch process was reduced to simple level, temperature, and mixing control operations with emphasis on simplifying the overall programming task and more focus on the key safety and operational issues. Great care and safety precaution must be taken during the debugging / testing and thus this task cannot be delegated to non-experts. Batch process control requires a multi-facets expert domains; thus review, certification and approval is a must throughout process specification, design, implementation, and checkout. In the vast majority of projects, the entire debugging task including the time intensive static input / output wiring / instrumentation calibration must be run / supervised by the expert PLC programmer with adequate technician and batch process domain experts support as needed.

\section{References}

[1] Eman Kamel and Khaled Kamel, "Hands-On PLC Programming with RSLogix 500 and LogixPro", McGrewHill professional, (ISBN-13: 978-1259644344), August 2016.

[2] Khaled Kamel and Eman Kamel, "Programmable Logic Controllers: Industrial Control", First Edition, McGraw-Hill Professional (ISBN: 0071810455/9780071810456), August 2013.

[3] L.Chitra, Siranjeevi.S, Manikandan.A, Saravanan.G, "Automation of Batch Production in Paint Industry using PLC", International Journal of Innovative Technology and Exploring Engineering (IJITEE) ISSN: 2278-3075, Volume-9 Issue-2S4, December 2019.

[4] Batch Process Skid Solutions, Mixing \& Blending Control System Solutions for OEMs., https://literature.rockwellautomation.com/idc/groups/literature/documents/wp/proces-wp001_en-p.pdf

[5] Khaled Kamel and Eman Kamel, "Waste Water Treatment Wet wells Pump Station PLC Control", International Journal of Science and Engineering Technology, Vol. 1, October 2015.

[6] Khaled Kamel and Eman Kamel, "PLC Motor Control Fundamentals and Safety Features: A Case Study", Journal of Computer Science Applications and Information Technology, December 2018.

[7] Matt Ruth Avanceon, "Evaluating the ISA 88 standard for batch control", March 6, 2018,

[8] https://www.controleng.com/articles/evaluating-the-isa-88-standard-for-batch-control/.

ISSN: 2582-3825 (online)

Submitted: 14.04 .2020

Accepted: 01.06.2020

Published: 09.06.2020 